\title{
Constitutional factors of autarcesis of the Orenburg goats
}

\author{
S.V. Nikitina* \\ Orenburg State Agrarian University, Orenburg, Russia
}

\begin{abstract}
The paper shows the results of a comparative assessment of the seasonal and age patterns of autarcesis in Orenburg goats. Intact healthy goats were studied as control groups: 1st experimental group - breeding male goats $(\mathrm{n}=10)$, 2nd group - breeding female goats $(\mathrm{n}=10)$, 3rd experimental group - gimmer hogs $(\mathrm{n}=10)$, and 4 th experimental group young wethers $(\mathrm{n}=10)$. The autarcesis is marked by humoral factors, for example, indicators of the bactericidal activity of the blood serum, lysozyme activity, and beta-lytic activity (thrombodefensin activity). The investigations have shown that the maximum values of the bactericidal activity of the blood serum were found in the autumn and winter times in the experimental groups. Their values were $73,75 \pm 1,07 \%, 78,28 \pm 0,85 \%$, $65,89 \pm 1,16 \%$, and $71,16 \pm 0,71 \%$, respectively. The minimum values are determined in spring and summer. A similar pattern was found in the study of beta-lytic activity in the autumn-winter time, but the highest values were observed in the animals of the experimental group of $9.43 \pm 0.12 \%$ and $9.86 \pm 0.15 \%$, respectively. The decrease in the bactericidal activity of the blood and the beta-lytic activity in the summer time was recompensed by the values of lysozyme activity. Thus, the highest immunological indices were found in summer time. The highest values of white blood cells were found in the blood of the gimmer hogs and young wethers. Meanwhile, the studied indicators did not overstep the limits of the physiological standard. The data obtained are suggested to be used in breeding work for the reproduction of animals with a high level of autarcesis.
\end{abstract}

\section{Introduction}

Autarcesis includes mechanisms of non-specific protection factors. It is associated with metabolism, with particular, individual, and constitutional characteristics of the body [1]. In evolution, autarcesis has developed a strategic ability to respond to the invasion of an exogenous agent and a damaging factor. Under genetic control, the inborn immune system rapidly mobilizes humoral and cellular defense factors [2]. The tolerance of a growing organism is formed gradually and finally determined at a certain stage of physiological maturation with the fulfillment of a certain age and maturity. Different age periods of animals are marked by varying tolerance to diseases and environmental factors. With the growth and development of the body, the level of autarcesis is progressively more complex,

\footnotetext{
* Corresponding author: grin229n123@mail.ru
} 
which is related to the improvement of adaptive physiological mechanisms in the direct interaction of the body with external environmental factors. There is data that climatic conditions connected with the seasons result in a number of changes in autarcesis indicators of animals [3-5]. It must be noted that the effects of natural and climatic factors on the level of autarcesis are very controversial, and the mechanisms of their influence are not clear yet.

The Orenburg breed of goats was formed as a consequence of natural selection, because of adaptation to severe climatic conditions and long-term folk selection. The priority direction of selection and breeding work is to keep high productive and technological properties of down in the Orenburg breed of goats, while the peculiarity of the breed is pronounced locality. If the animals are moved to other natural and climatic conditions, the economic and production characteristics degrade [6-9]. The study was performed in the conditions of the sharply continental climate of the Orenburg region, where the fastgrowing season of steppe vegetation and the low productivity of pastures in the summer are typical.

The purpose of the paper is to perform a comparative assessment of the seasonal and age dynamics of the autarcesis of Orenburg goats.

\section{Materials and methods}

The research was done on goats of the Orenburg breed in the conditions of the pedigree breeding unit - "Donskoy" APC of the Orenburg region. 40 animals were chosen for the experiment. They were divided into four groups. Every group consisted of intact clinically healthy goats, with 10 heads in each group. 1st experimental group - breeding male goats (4 years), $2^{\text {nd }}$ experimental group - breeding female goats (4 years), $3^{\text {rd }}$ and $4^{\text {th }}$ experimental groups - gimmer hogs and young wethers at the age of 12 months.

The animals were kept in the same technological conditions. The bactericidal activity was defined by the method of O. V. Bukharin and V. L. Sozykin (1972) using the test culture of E. coli Om. Lysozyme activity was investigated according to O. V. Bukharin (1971) using a daily agar culture of Micrococcus luteus (strain N 2665 of the L. A. Tarasevich Scientific Centre for Expert Evaluation of Medicinal Products). Thrombodefensin activity was investigated by the photonephelometric method according to O. V. Bukharin et al. (1972). B. subtilis (strain N 83 of the L. A. Tarasevich Scientific Centre for Expert Evaluation of Medicinal Products) was utilized as a test culture. Hematological indicators were detected using a PCE-90 VetMindray analyzer. The evaluation of the reliability of the differences in the compared samples was defined by the Student's t-test.

\section{Results and discussion}

The studies have demonstrated that non-specific protective factors, in a comparative aspect, differ in the age groups of the studied animals and in their expressions rely on the season. The bactericidal activity of blood serum (BABS) is part of the innate immune system, has a wide spectrum of antimicrobial action, reflects the functional condition and forms the protective properties of the body. The analysis of the received studies revealed that the highest values of the bactericidal activity of blood serum in the experimental groups were found in winter. Meanwhile, the intergroup distinctiveness of the studied indicator was noted. In the 1st experimental group, consisting of breeding male goats, the BABS had the highest values and amounted to $78.28 \pm 0.85 \%$. In the group of breeding female goats, the bactericidal activity is $9.1 \%$ lower than the values of the 1st group. Analyzing the results, it was observed that in the age aspect, the bactericidal activity of blood serum enhances its 
values. In this regard, in the 3rd and 4th groups, the indicator was- $70.09 \pm 0.71 \%$ and $62.96 \pm 0.85 \%$, respectively (Fig. 1 ).

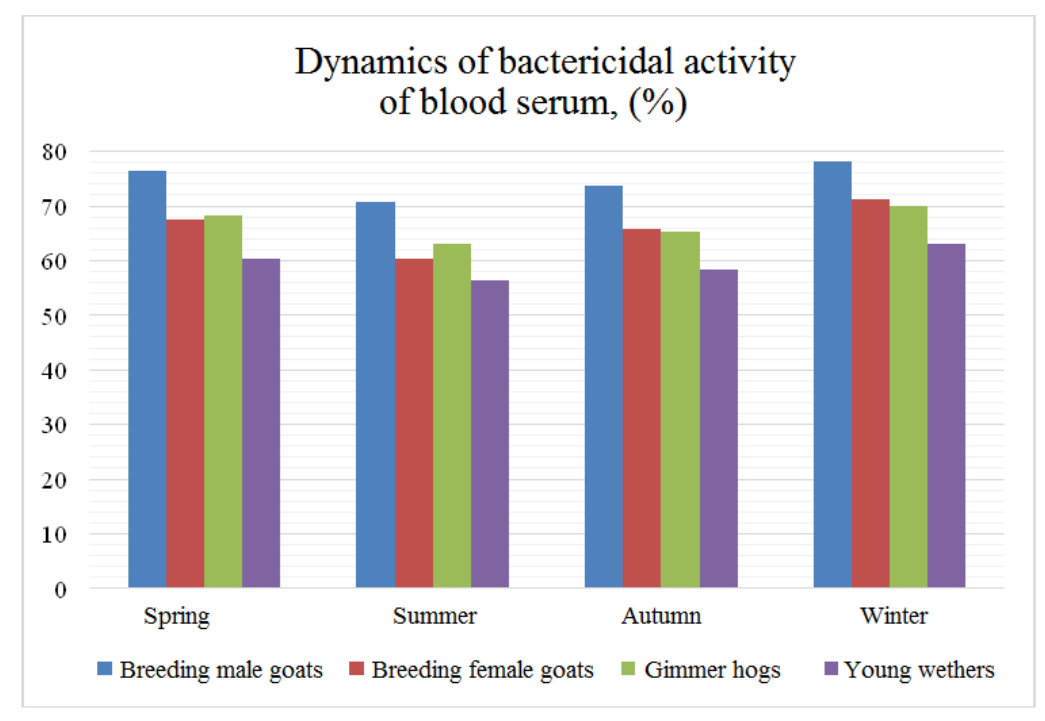

Fig. 1. Dynamics of bactericidal activity of blood serum, $\%$.

The lowest activity is registered in summer. In this regard, the studied indicator in the groups was- $70.75 \pm 0.67 \%$ (1st gr.) and $60.28 \pm 1.36 \%$ (2nd gr). The minimum activity was established in the blood of young wethers and made up $56.29 \pm 1.35 \%$. In the group of gimmer hogs, the bactericidal activity is $12 \%$ higher than the minimum values. In spring, the studied index slightly differed from the ones of autumn. Meanwhile, the bactericidal activity of blood in autumn was registered with lower values in all the studied groups of animals.

One of the factors of autarcesis which fulfills the antimicrobial activity of the blood serum is the serum protein beta-lysine. It disrupts the permeability of the membrane of pathogenic microorganisms. By the degree of beta-lytic activity of the blood serum, the state of autarcesis, the level of physiological processes, and the pathological condition are assessed. A comparison of the seasonal dynamics of beta-lytic activity of goat blood serum revealed the maximum values in autumn-winter, and the minimum reference values in spring and summer [10-12]. For example, in 1st experimental group, the indicators of the autumn-winter period were $8.17 \pm 0.18 \%$ and $9.28 \pm 0.22 \%$, respectively. In spring and summer, this indicator is noted at the level of $6,44 \pm 0,13 \%, 7,22 \pm 0,19 \%$. In the experimental group of breeding female goats, the indicators of b-lytic activity were $5 \%$ lower in winter and $2.3 \%$ lower in autumn than the reference values of the experimental group. In spring and summer, the indicators of breeding female goats did not vary much from the values of the 1st experimental group. It must be noted that the largest reference values in the compared groups had gimmer hogs. 


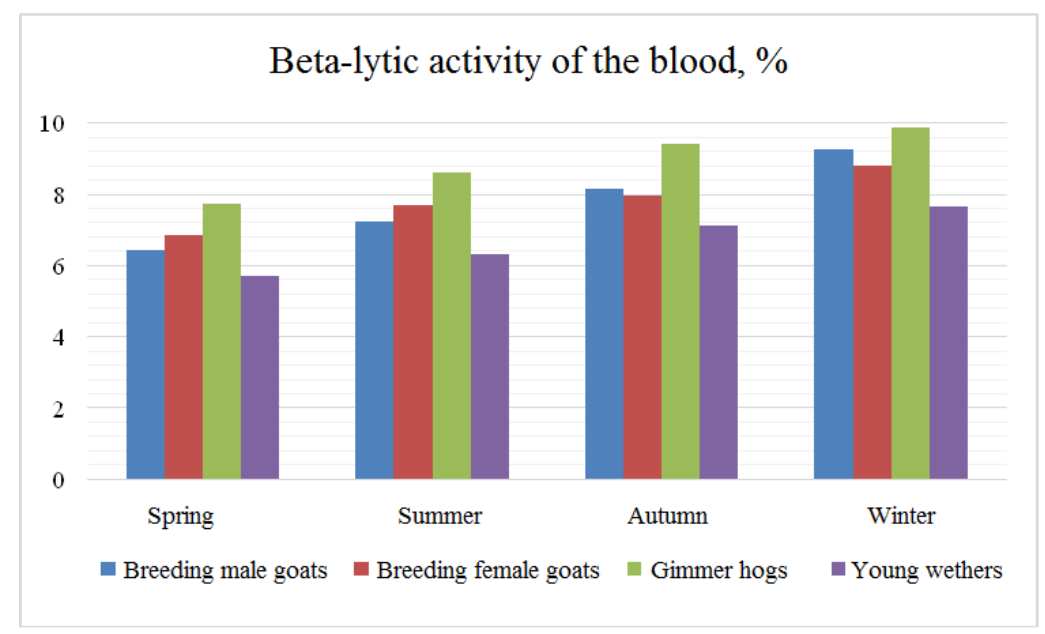

Fig.2. Beta-lytic activity of the blood, $\%$.

Thus, in the autumn and winter, the level of b-lytic activity was $9.43 \pm 0.12 \%$ and $9.86 \pm 0.15 \%$, respectively (Fig.2). Summer activity indicators are $12.6 \%$ lower than winter ones. In the spring months, the minimum reference values for the group were $7.72 \pm 0.13 \%$. In the 4th experimental group, according to the seasons, b-lytic activity was the lowest of the reference values. Meanwhile, the studied indicators did not exceed the limits of the physiological standard. The temperature condition of the environment is the most significant factor. In the process of life, the body adapts to the temperature factor in order to survive. Thus, the increase in activity in winter is caused by the mobilization of the body's protective features to adverse environmental conditions. Meanwhile, the minimum temperature values of the environment trigger compensatory mechanisms. High temperature conditions affect the rate of physiological and biochemical reactions. The decrease in BABS activity and beta-lytic activity in summer is due to high solar radiation, tension of the thermal balance, redistribution of fluid in the body, and a decline in the level of feed consumption. In this period, the steppe pastures in this region have a low nutritional value.

The antibacterial enzyme, lysozyme, is found in many animal tissues and body fluids. They produce white blood cells, secreting it into the bloodstream. A reduction in the concentration of lysozyme can cause the development of an infectious process. [13]. Analyzing the results of the study of the lysozyme activity of blood serum, it was determined that the highest immunological indicators were seen in summer. In the relative aspect, the animals of the 1st and 2nd experimental groups had the highest reference values, which was $6.30 \pm 0.28 \%$ and $7.48 \pm 0.17 \%$, respectively. Meanwhile, in summer, lysozyme activity of the blood serum was $29.2 \%$ higher in young wethers (4th group) than in gimmer hogs (2nd group). 


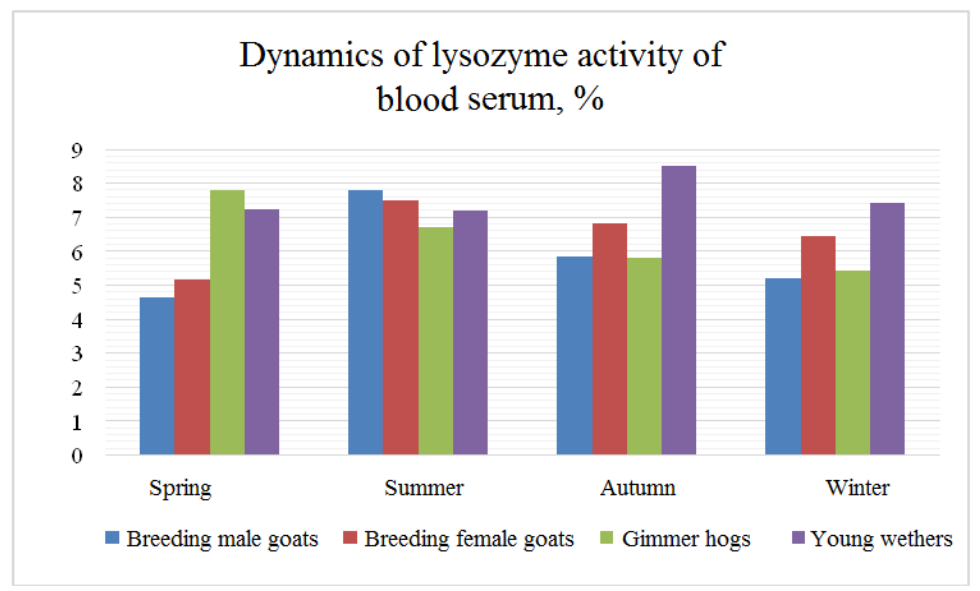

Fig.3. Dynamics of lysozyme activity of blood serum, $\%$.

The lowest reference values in the compared groups were found in spring. Nevertheless, in this time of the year, the highest values of the indicators were found in the young wethers group- $7.23 \pm 0.15 \%$, while the minimum reference values were in the gimmer hogs group$4.80 \pm 0.20 \%$. It must be noted that during winter, the lysozyme activity of the blood serum indicators differed slightly from the autumn ones, while the lysozyme activity in the autumn months was of great importance.

Leukocytes play an important biological role in the body of animals, ensuring the development of specific immunological defense mechanisms. The number of leukocytes in the blood is a diagnostic index and has important clinical significance. The analysis of the parameters of the seasonal dynamics of the white blood pattern revealed a higher concentration of leukocytes in winter. The minimum values were determined in summer. The number of leukocytes in the blood in spring did not considerably differ from the autumn indicators. Therefore, the maximum winter reference values were $11.48 \pm 0.34109 / 1$ (1st group), $11.36 \pm 0.30109 / \mathrm{L}$ (2nd group), 13.63 $\pm 0.10109 / \mathrm{L}$ (3rd group), and 13.39 \pm 0.16 109/L (4th group). Meanwhile, the leucocytes of gimmer hogs and young wethers had the maximum values. The findings indicate that there are patterns in the dynamics of the content of leukocytes. Therefore, with age, there is a decrease in the studied indicator [14$15]$.

\section{Conclusion}

The combination of natural and environmental factors which characterize the specificity of the region influences the levels of the structural organization of the animal. They promote changes in the activity of regulatory mechanisms and homeostatic functions. The dynamic changes that occur in the blood of goats are related to age and the season. The results revealed that the highest values of bactericidal and beta-lytic activity were found in autumn and winter. In the comparison of the age aspect, the maximum BABS values were found in the experimental groups of breeding male and female goats, and the maximum values of the beta-lytic activity were found in the group of gimmer hogs. The decrease in BABS and beta-lytic activity in summer was recompensed by the values of lysozyme activity. The highest immunological indices were found in summer in the groups of gimmer hogs and young wethers. Also, the highest values of leucocytes were observed in these groups. In the study, the factors of autarcesis were not beyond the limits of the physiological standard. The strategy of developing the breed and reproduction of goats by the method of purebred 
breeding in order to ensure high wool (down) efficiency is based on the selection of animals with high autarcesis and the best adaptive abilities to the adverse factors of the environment.

\section{References}

1. V.M. Meshkov, On the question of seasonal changes in the natural resistance of goats, Stavropol, 135-137 (1989)

2. A.I. Shevchenko, S.A. Shevchenko, Agr. Biol, 2, 93-98 (2013)

3. A.I. Glazunov, V.N. Guschin, B.B. Shishov, Zootech, 7, 24-27 (1990)

4. M.V. Zabelina, A.S. Novichkov, E.I. Grigorashkina, Sh. G. \& W. B, 3, 12-15 (2014)

5. S.G. Kanatbaev, R.A. Amanzhol, Seasonal dynamics of autarcesis of goats in the West Kazakhstan region, Center rezvitiya nauchnogo sotrudnichestva, 15-19 (2014)

6. A.N. Ekimov, Use of bioresource potential of Orenburg goats - state support, Orenburg, 255-262 (2007)

7. Yu.N. Kamneva, O.N. Bezverkhaya, Youn. Resear, 7, 300-304 (2016)

8. L.K. Marzanova, A.N. Ekimov, N.S. Marzanov, N.N. Pushkarev, Y.S.Marzanov, M.G. Nasibov, Blood groups of goats of the Orenburg breed, Germany, 118 (2002)

9. N.N. Pushkarev, Proc. of the Oren. St. Ag. Un, 2(65), 152-154, (2017)

10. V.M. Meshkov, M.V. Sycheva, Proc. of the Oren. St. Ag. Un, 109-111 (2008)

11. A.B. Korovin, A.S. Karamaeva, A.M. Belousova, Proc. of the Oren. St. Ag. Un, 99102 (2013)

12. V.Ya. Sarukhanov, I.M. Kolganov, P.G. Tsarin, Bull. of the Nat. Radi. Epid. Reg, 25(1), 108-114 (2016)

13. V.Ya. Sarukhanov, N.N. Isamov, I.M. Kolganov, Ag. Biol, 2, 119-122 (2012)

14. S.V. Nikitina, L.G. Kislinskaya, Seasonal changes in physiological parameters in goats of the Orenburg down breed, Perspektiva, Orenburg, 65-66 (2008)

15. V.I. Kosilov, P.N. Shkilev, E.A. Nikonova, Coll. of Sc. Pap. of the Stav. Res. Inst. of An. Husban. \& F. Prod, 1(6), 53-64 (2013) 